\title{
Programmed cell death eliminates all but one embryo in a polyembryonic plant seed
}

\author{
LH Filonova ${ }^{1}$, S von Arnold', G Daniel ${ }^{2}$ and PV Bozhkov ${ }^{*, 1}$ \\ 1 Department of Forest Genetics, Swedish University of Agricultural Sciences, \\ Box 7027, S-75007 Uppsala, Sweden \\ 2 Department of Wood Science, Swedish University of Agricultural Sciences, \\ Box 7008, S-75007 Uppsala, Sweden \\ * Corresponding author: Dr PV Bozhkov, Department of Forest Genetics, \\ Swedish University of Agricultural Sciences, Box 7027, S-75007 Uppsala, \\ Sweden. Tel: 46-18-673228; Fax: 46-18-673279; \\ E-mail: Peter.Bozhkov@sgen.slu.se
}

Received 31.1.02; revised 15.3.02; accepted 8.4.02

Edited by M Piacentini

\begin{abstract}
Development of multiple embryos from a single zygote, the phenomenon called monozygotic polyembryony, is a widespread reproductive strategy found in higher plants and especially in gymnosperms. The enigma of plant monozygotic polyembryony is that only one embryo in a polyembryonic seed usually survives while the others are eliminated at an early stage. Here we report that programmed cell death (PCD) is the major mechanism responsible for elimination of subordinate embryos in a polyembryonic seed. Using postfertilized pine (Pinus sylvestris) ovules, we show that once the dominant embryo is selected and, subsequently, the entire female gametophyte is affected by PCD, the cells of subordinate embryos initiate an autolytic self-destruction program. The progression of embryonic PCD follows a rigid basal-apical pattern, first killing the most basally situated cells, adjacent to the suspensor, and then proceeding towards the apical region until all cells in the embryonal mass are doomed. Our data demonstrate that during polyembryony, PCD serves to halt competition among monozygotic embryos in order to ensure survival of one embryo.
\end{abstract}

Cell Death and Differentiation (2002) 9, 1057-1062. doi:10.1038/sj.cdd.4401068

Keywords: programmed cell death; polyembryony; plant seed; embryo competition; female gametophyte; embryo elimination

Abbreviations: DAPI, 4'-6-diamino-2-phenylindole; PCD, programmed cell death; TUNEL, terminal deoxynucleotydil transferase (TdT)-mediated dUTP nick-end labeling; waf, weeks after fertilization

\section{Introduction}

During evolution of multicellular eukaryotes, certain approaches to clonal propagation have been developed.
Some species have embryogenesis programs involving physical splitting of cells, after the first few mitotic divisions, into separate embryos. Other species show self-cloning at the level of post-embryonic, but pre-adult, individual (larva). In both cases of monozygotic polyembryony, offspring are derived from the same zygote and therefore are genetically identical to each other, but distinct from their parent(s). In animals, obligate monozygotic polyembryony has been documented on at least 18 occasions within bryozoans, hydrozoans, parasitoid wasps, flatworms and armadillos. ${ }^{1}$ Furthermore, accidental or 'sporadic' polyembryony in a form of monozygotic twinning occurs at a very low frequency in humans and some other mammals. ${ }^{2}$ In plants, monozygotic polyembryony is a more widespread reproductive strategy, ${ }^{3}$ being especially common among gymnosperms where at least 20 genera have evolved so called 'cleavage polyembryony'. ${ }^{4}$ One embryo in a polyembryonic seed usually develops to maturity and gives rise to a viable plant while all the other embryos are eliminated at early developmental stages. ${ }^{4-7}$ The mechanism responsible for eliminating plant embryos is unknown.

The developing pine seed represents a good model system for studying plant embryo elimination, because multiple pine embryos which arise from the same zygote through obligate cleavage polyembryony ${ }^{4,5,7}$ coexist in the same environment (in a corrosion cavity within the female gametophyte ${ }^{4}$ ), and develop in close proximity to each other during early and late embryogeny. Here we show that programmed cell death (PCD) is the major mechanism responsible for elimination of all but one embryo in a polyembryonic pine seed.

\section{Results and Discussion}

\section{Programmed cell death eliminates subordinate embryos}

A hallmark feature of pine embryogeny is that a single, zygotederived early embryo (Figure 1; 1 week after fertilization (waf)) cleaves to form multiple (in the range from four to several dozen) embryos of equal size (Figure 1; 2 waf). One embryo becomes dominant (Figure $1 ; 3$ and 4 waf) while the subordinate embryos are eliminated (Figure 1; 6 and 11 waf). The entire period of post-fertilized pine ovule development can be divided into three phases, in terms of embryo competition. During the first, brief phase, all the embryos in an ovule have similar growth rates and thus have an equal opportunity for dominance (Figure 1; 2 waf). The onset of the second, longer phase, coincides with one embryo 'gaining a victory' in the competition and becoming dominant (Figure 1; 3 waf). The growth of remaining, subordinate embryos, is progressively reduced (Figure 1; 4 waf) until it stops completely when the dominant embryo has reached the cotyledonary stage (Figure 1; 6 waf). During the third phase, 
subordinate embryos are progressively eliminated, while the mature dominant embryo enters the dormancy period (Figure 1; from 6 waf onward).

To determine the kinetics of the elimination of subordinate embryos, we scored the number of polyembryonic ovules at different times after fertilization. We defined a 3week period (between 8 and 11 waf) during which about $80 \%$ of the ovules were completely cleared of subordinate embryos, thus becoming monoembryonic. The clearance of remaining polyembryonic ovules (about $20 \%$, most of which tended to contain subordinate embryos of greater size) was slow and asynchronous, sometimes being delayed until seed germination (data not shown, see also refs ${ }^{5,8}$ ).

Is elimination of subordinate pine embryos another example of developmental PCD? ${ }^{9-12}$ We analyzed nuclear DNA integrity in embryos at different times during ovule development using terminal deoxynucleotydil transferase (TdT)-mediated dUTP nick-end labeling (TUNEL). A highly ordered pattern of DNA fragmentation was detected in subordinate embryos (Figure 2) but not in the dominant embryo (data not shown). The embryo suspensor was the only embryonic structure undergoing DNA fragmentation during embryo competition, as no TUNEL positive cells were found in embryonal masses at 2 and 4 waf (Figure 2). Once the dominant embryo had reached the cotyledonary stage at 6 waf (Figure 1), a small subset of the most basally situated cells within the embryonal mass of subordinate embryos displayed DNA fragmentation (Figure 2; 6 waf). This seemed to determine the major 'course' of nuclear degradation, as it progressively spread towards the apical region of the subordinate embryos until all the cells of the embryonal masses were doomed (Figure 2; 8 and 10 waf). Such a regular pattern of DNA fragmentation was invariably followed by all the subordinate embryos analyzed, indicating its programmed nature. Rapid accumulation of subordinate embryos with fragmented DNA was clearly followed by a drop in the frequency of polyembryonic ovules (Figure 3).

Since the presence of nuclear DNA fragmentation did not explain the way subordinate embryos are eliminated from the ovules, we analyzed the ultrastructure of dying cells in the embryonal masses. These cells displayed cooperative autolytic and autophagic mechanisms of protoplast degradation (Figure 4). The cytoplasm and organelles were gradually engulfed and lysed by a high number of growing vacuoles (Figure 4A,B). This slow phase of cell degradation was followed by a brief culminate phase triggered by vacuole collapse and leading to complete protoplast removal (Figure $4 \mathrm{C}$ ). This pathway of cell dismantling is known to be activated in those plant developmental deaths, including embryo suspensor death, ${ }^{13}$ which require substantial or complete processing of cell corpses. ${ }^{12,14}$ Thus it is not altogether surprising that most pine ovules do not contain subordinate embryos at late stages.

\section{Dying cells of female gametophyte are not subjected to rapid destruction}

Our data do not currently allow us to determine the signal triggering cell death in subordinate embryos in a pine seed. We, however, speculate that this signal might be given by the female gametophyte (haploid maternal tissue which has similar functions as the endosperm in angiosperm seeds ${ }^{4,15}$ ) as a response to depletion of a pool of growth factors which becomes too low to support complete development of all embryos in a seed. ${ }^{15-18}$ If so, the viability of the female gametophyte would cease prior to cell death in subordinate embryos. Noteworthy, PCD in a gymnosperm female gametophyte has not previously been identified, whereas angiosperm endosperm has been shown to initiate suicide program either before or during seed germination. ${ }^{19,20}$

Indeed, we did find a highly organized pattern of progression of nuclear DNA fragmentation (one of the well-known hallmarks of endosperm $\mathrm{PCD}^{19}$ ) throughout the female gametophyte (Figure 5A). At the time when the dominant embryo has been selected and started active growth, all the cells in the female gametophyte seem to be viable (Figure 5A; 3 waf, upper row), except for a narrow, unicellular layer that lines the corrosion cavity (Figure $5 \mathrm{~A} ; 3$ waf, second row). These cells are thought to function in embryo nutrition. ${ }^{21}$ Thereafter the cone-shaped zone in front of the dominant embryo began to degenerate making room for the actively growing embryo (Figure 5A; 4 waf). The entire female gametophyte was affected by DNA fragmentation shortly before the first signs of $P C D$ in the embryonal masses of subordinate embryos (Figure $5 \mathrm{~A} ; 5$ waf). Like in the case of a well-described PCD pathway of maize endosperm, ${ }^{19}$ it requires approximately 2 weeks to
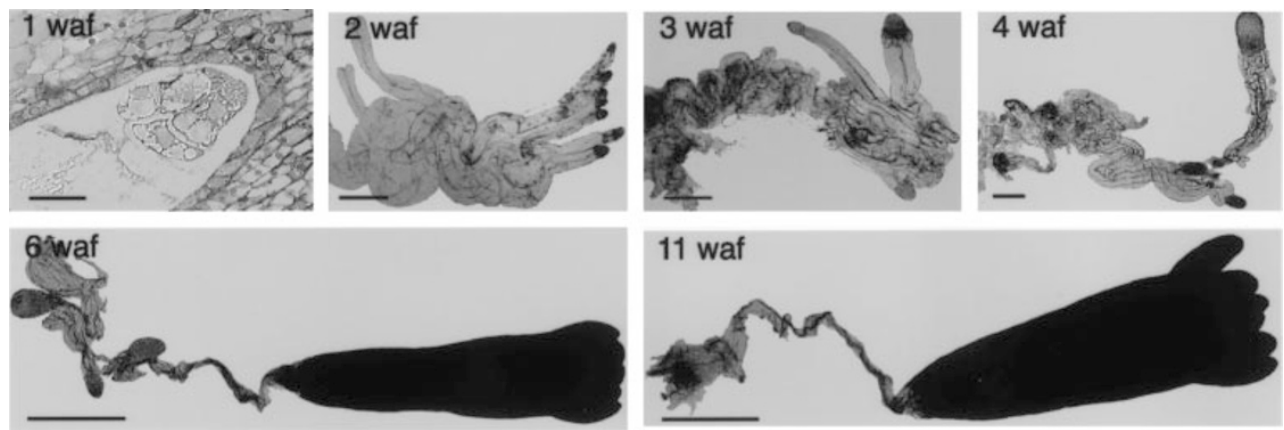

Figure 1 The pathway of monozygotic polyembryony in a pine seed leading to elimination of subordinate embryos. waf, weeks after fertilization. Scale bars: 1 waf, $50 \mu \mathrm{m} ; 2-11$ waf, $500 \mu \mathrm{m}$ 


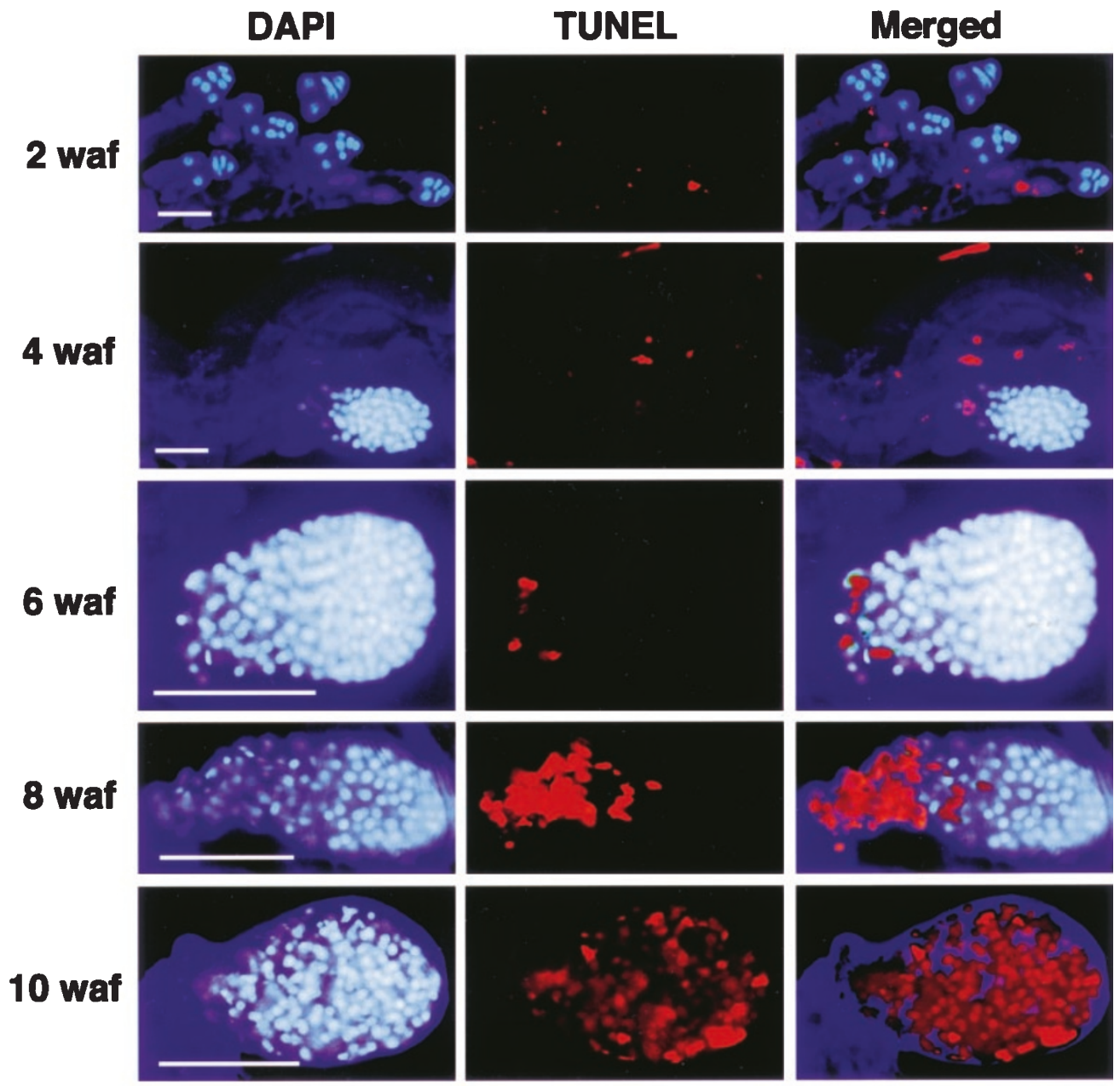

Figure 2 Spatio-temporal pattern of PCD in the subordinate embryos. Whole mounts of embryos were assayed by TUNEL and counterstained with DAPI at successive developmental stages. Localization of nuclei with fragmented DNA is represented by red fluorescence. From 4 waf onward only subordinate embryos are shown. Scale bars, $100 \mu \mathrm{m}$

program all the cells within a pine female gametophyte to die. Unlike full-blown cell corpses of subordinate embryos, the dying cells of the female gametophyte are not subjected to rapid destruction but rather persist as depositories of carbon (in lipid bodies ${ }^{22}$ ) and nitrogen (in protein storage vacuoles ${ }^{23}$ ) that will be used by the embryo upon germination (Figure 5B).

\section{Cooperation of two distinct cell death programs in polyembryonic seed}

Our results provide the first evidence that PCD plays a central role in the regulation of embryo number in polyembryonic seeds (Figure 6). Like animal apoptosis, which acts as a part of quality-control mechanism by compensating for genetic or stochastic developmental errors ${ }^{11}$ as well as by controlling cell numbers under limiting amounts of survival signals, ${ }^{9}$ embryonic cell death in the pine seed ablates surplus embryos and so adjusts embryo number to the net amounts of growth factors supplied by the female gametophyte, thus providing a free avenue for one embryo to develop into a plant. The pathway 'all but one embryo die' described in the present study does not, however, seem to be an absolute rule for development of polyembryonic pine seeds. Certain conditions, including growth in arctic regions ${ }^{5,7}$ and the presence of massive female gametophyte, ${ }^{8}$ can allow complete development of more than one embryo in a single pine seed, indicating a high level of plasticity in the activation of embryo autodestruct mechanism.

Being in its infancy, PCD research in plants has however already demonstrated that different cell types can recruit different down-stream death execution programs resulting in different magnitudes of cell corpse autoprocessing. $^{12,14,24}$ As shown in this study, developing pine seed coordinates two death programs that are initiated in tandem in two different structures displaying two contrasting pathways of cell dismantling. One program, affecting the female gametophyte, is likely triggered by a cue given by rapidly growing embryos (Figure 6, stage II), and its developmental roles are to make room for the dominant embryo (Figure 6, stage III) and to prepare 


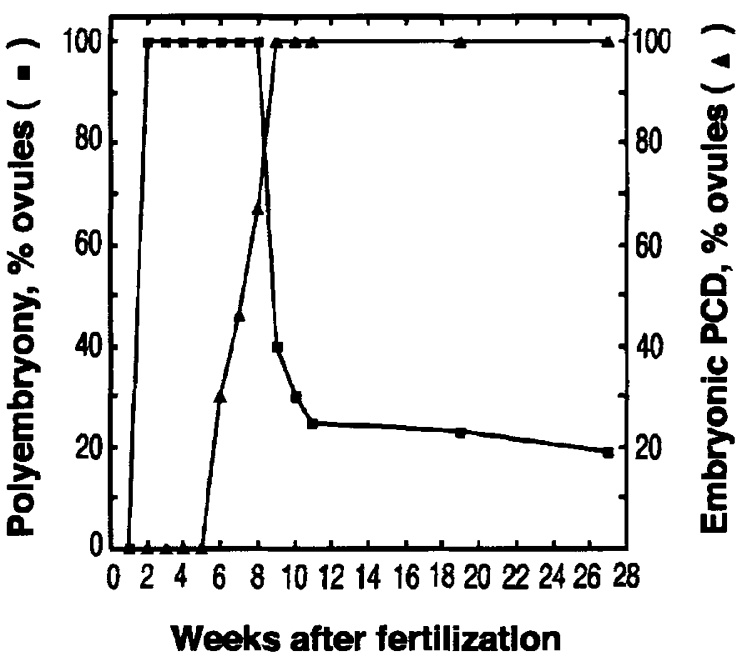

Figure 3 Correlation between the kinetics of the frequencies of polyembryonic ovules and embryonic PCD. The frequency of polyembryonic ovules was calculated as the fraction of ovules containing more than one embryo (made visible by DAPI staining) out of the total number of ovules analyzed (at least 50 ovules at each sampling time point). The frequency of PCD was determined by calculating the fraction of polyembryonic ovules containing at least one subordinate embryo displaying TUNEL positive cells within the embryonal mass. At least 20 ovules at each sampling time point were assayed by TUNEL. Results are expressed as means of two independent observations carried out on two successive years

functional cell corpses to store nutrients (Figure 6, stage IV) necessary to support germination and seedling growth. This program is followed by a second cell death program that acts to ablate surplus embryos in a seed through complete autolytic destruction of cell protoplasts (Figure 6, stages $\mathrm{V}-\mathrm{VII})$. Orchestrated action of these two death programs creates a viable seed containing both a single welldeveloped living embryo and nutrient reserves packed within preserved cell corpses in the female gametophyte (Figure 6, stage VIII). This work provides the first experimental system to study molecular mechanisms of natural embryonic cell death in plants.

\section{Materials and Methods}

The donor of plant material was a 30-year-old Scots pine (Pinus sylvestris) tree growing at a local dendrarium (Uppsala, Sweden, latitude $59^{\circ} 31^{\prime}$, longitude $17^{\circ} 31^{\prime}$ ). The ovules were collected for analyses during the period June-December on two successive years $(2000,2001)$. Fertilization time was determined through day-by-day microscopy inspection of 50 ovules at a time. Considering a small variation in fertilization dynamics between different ovules, 'the weeks after fertilization (waf)' were counted from the day when half of the ovules were fertilized (June 13, 2000 and June 21, 2001). The counts for the frequencies of polyembryonic ovules, as well as TUNEL analysis of embryos and female gametophytes were made during two successive years, first on a weekly basis, from 1 to 11 waf, and then additionally at 19 and 27 waf during seed dormancy. For TUNEL, whole mounts of monozygotic embryos and serial sections of female gametophytes were prepared from at least 20 polyembryonic ovules at each sampling time. All the procedures for fixation, embedding and TUNEL were previously described, ${ }^{13}$ the only difference being that
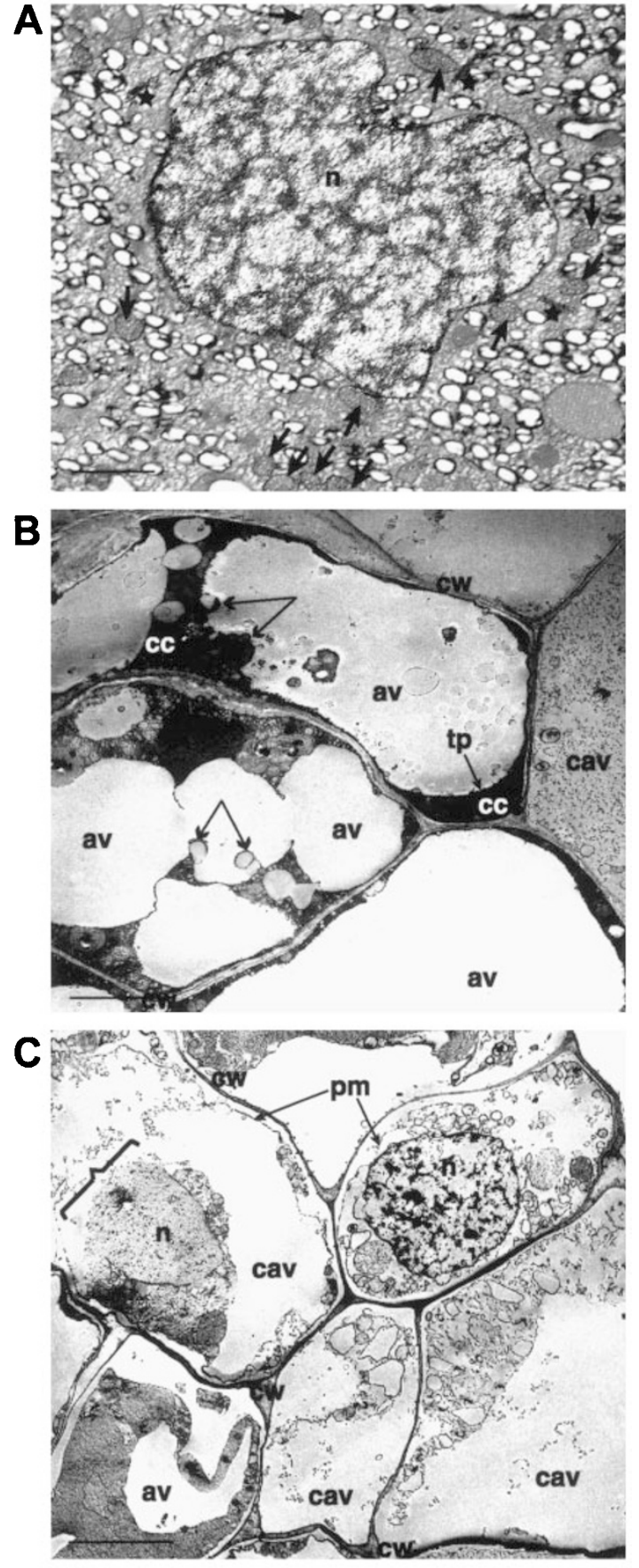

Figure 4 Degradation of the protoplasts in subordinate embryos observed by transmission electron microscopy at 6 waf $(\mathbf{A}), 8$ waf $(\mathbf{B})$ and 10 waf $(\mathbf{C})$. (A) Formation of numerous small provacuoles and lobing of nucleus $(n)$ are early markers of this PCD. Several Golgi complexes in a cell are indicated by asterisks. The mitochondria (arrows) remain morphologically intact. (B) Largescale vacuolation proceeds through the fusion of autolytic vacuoles (av) and engulfment of provacuoles and portions of the cytoplasm (double arrows). Highly condensed cytoplasm (cc) is confined between tonoplast (tp) and cell wall (cw). (C) Rupture of tonoplast leads to complete lysis of the protoplast, including nucleus ( $n$, bracket), by collapsed autolytic vacuoles (cav). Plasma membrane $(\mathrm{pm})$ is shrunken and detached from the cell wall (cw). Scale bars: $5 \mu \mathrm{m}$ in $\mathbf{A} ; 10 \mu \mathrm{m}$ in $\mathbf{B}, \mathbf{C}$ 

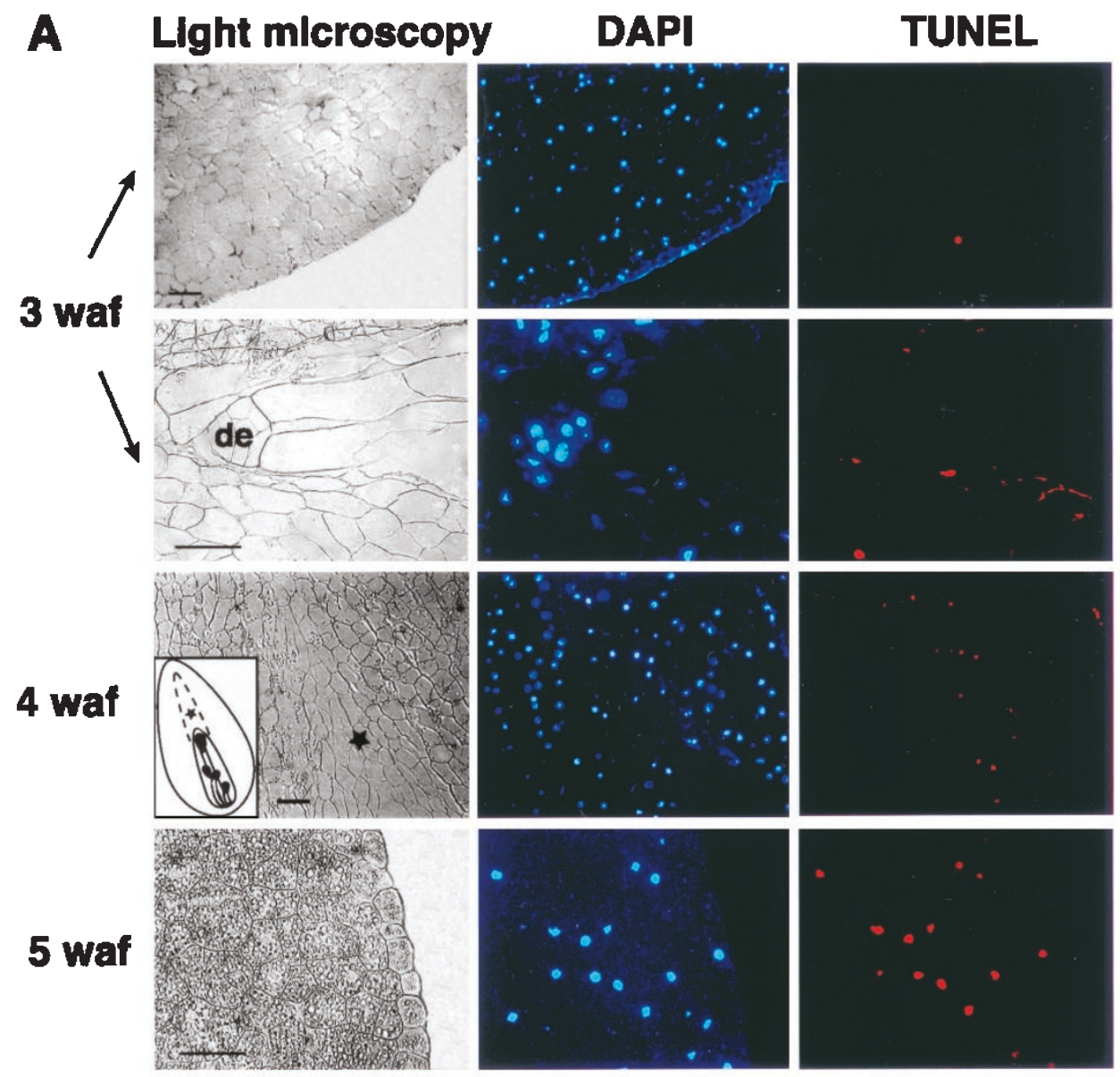

B

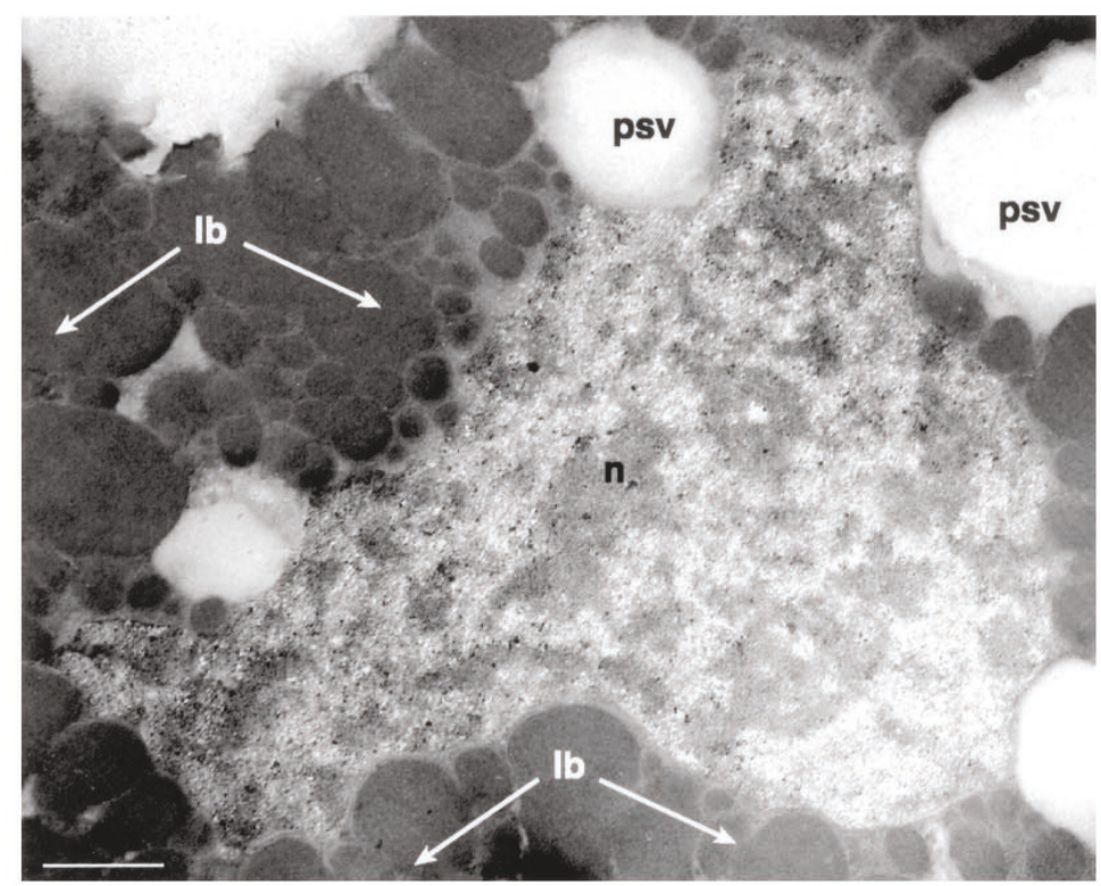

Figure 5 Programmed cell death in the female gametophyte. (A) Sections of female gametophytes were assayed by TUNEL and counterstained with DAPI at successive developmental stages. Shown to the left are the views of the same sections under light microscopy. Localization of nuclei with fragmented DNA is represented by red fluorescence. Insert (4 waf) shows the location of the dome-shaped region (asterisk), on the path of dominant embryo (de) growth. Scale bars, $100 \mu \mathrm{m}$. (B) Preserved cell corpses in the female gametophyte observed by transmission electron microscopy at 5 waf. Note the presence of numerous lipid bodies (lb) and protein storage vacuoles (psv). Nucleus (n) is always lobed and crenulated. Scale bar, $1 \mu \mathrm{m}$ 
in plants

(2)

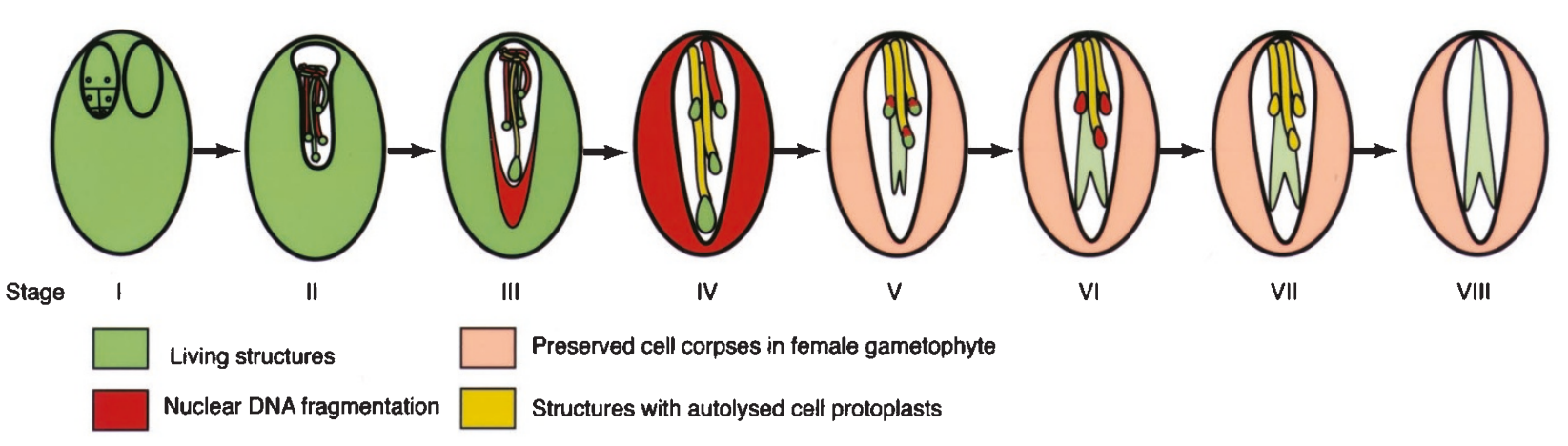

Figure 6 Schematic model showing cooperation of two major cell death programs during development of pine seed (not drawn to scale). During early development, a zygotic pine embryo (stage I) splits to form multiple embryos of the same genotype which start to compete for limited amounts of growth factors (stage II). Each embryo is composed of embryonal mass and suspensor. The latter is a terminally-differentiated structure undergoing PCD (stages II-IV ${ }^{13}$ ). Embryo competition requires a larger room to accommodate the rapidly growing dominant embryo, thus triggering cell death in the region of female gametophyte lying on the path of its growth (stage III). This locally induced cell death program rapidly progresses throughout the whole female gametophyte (stage IV). Dead cells of the female gametophyte are not however removed but rather persist as depositories of nutrients that will be required for embryo germination. Once the female gametophyte dies, another cell death program is activated in a seed with the aim to eliminate subordinate embryos. First affected are the most basally situated cells of embryonal masses (stage V). Cell death then spreads towards the apical regions until all the cells of subordinate embryos are committed to autodestruct (stages VI and VII). Such a coordinated tandem interplay between two cell death programs is what is responsible for development of the mature pine seed (stage VIII)

TMR red (red fluorescence) in situ cell death detection kit (Boehringer Mannheim) was used in the present study. Transmission electron microscopy was carried out essentially as described, ${ }^{13}$ with at least 10 samples of subordinate embryos or female gametophytes analysed at distinct developmental stages, between 5 and 10 waf.

\section{Acknowledgements}

We thank I Ekberg and L Grönroos for useful comments. This work was supported by The Troedssons Fund.

\section{References}

1. Craig SF, Slobodkin LB, Wray GA and Biermann CH (1997) The 'paradox' of polyembryony: A review of the cases and a hypothesis for its evolution. Evol. Ecol. 11: 127-143

2. Gleeson SK, Clark AB and Dugatkin LE (1994) Monozygotic twinning: An evolutionary hypothesis. Proc. Natl. Acad. Sci. USA 91: 11363-11367

3. Tisserat B, Esau EB and Murashige T (1979) Somatic embryogenesis in angiosperms. Hortic. Rev. 1:1-78

4. Singh H (1978) Embryology of Gymnosperms (Berlin: Borntrager)

5. Dogra PD (1967) Seed sterility and disturbances in embryogeny in conifers with particular reference to seed testing and tree breeding in Pinaceae. Stud. For. Suec. 45: 1-96

6. Bawa KS, Hedge SG, Ganeshaiah KN and Uma Shaanker R (1989) Embryo and seed abortion in plants. Nature 342: 625

7. Krutovskii KV and Politov DV (1995) Allozyme evidence for polyzygotic polyembryony in Siberian stone pine (Pinus sibirica Du Tour). Theor. Appl. Genet. 90: 811-818

8. Bozhkov PV, Ahn IS and Park YG (1997) Two alternative pathways of somatic embryo origin from polyembryonic mature stored seeds of Pinus koraiensis Sieb et Zucc. Can. J. Bot. 75: 509-512

9. Raff MC (1992) Social controls on cell survival and cell death. Nature 356: $397-$ 400
10. Conlon I and Raff M (1999) Size control in animal development. Cell 96:235-244

11. Meier P, Finch $A$ and Evan $G$ (2000) Apoptosis in development. Nature 407: 796-801

12. Beers EP and McDowell JM (2001) Regulation and execution of programmed cell death in response to pathogens, stress and developmental cues. Cur. Opin. Plant Biol. 4: 561-567

13. Filonova LH, Bozhkov PV, Brukhin VB, Daniel G, Zhivotovsky B and von Arnold S (2000) Two waves of programmed cell death occur during formation and development of somatic embryos in the gymnosperm, Norway spruce. J Cell Sci. 113: $4399-4411$

14. Jones AM (2001) Programmed cell death in development and defense. Plant Physiol. 125: $94-97$

15. Lopes MA and Larkins BA (1993) Endosperm origin, development and function. Plant Cell 5: 1383-1399

16. Kapik RH, Dinus RJ and Dean JFD (1995) Abscisic acid and zygotic embryogenesis in Pinus taeda. Tree Physiol. 15, 485-490

17. Hong SK, Kitano H, Satoh H and Nagato Y (1996) How is embryo size genetically regulated in rice? Development 122, 2051-2058

18. Chaudhury AM, Koltunow A, Payne T, Luo M, Tucker MR, Dennis ES and Peacock WJ (2001) Control of early seed development. Annu. Rev. Cell Dev. Biol. 17: 677-699

19. Young TE and Gallie DR (2000) Programmed cell death during endosperm development. Plant Mol. Biol. 44: 283-301

20. Schmid M, Simpson D and Gietl C (1999) Programmed cell death in castor bean endosperm is associated with the accumulation and release of a cysteine endopeptidase from ricinosomes. Proc. Natl. Acad. Sci. USA 96: 14159-14164

21. Olsen O-A (2001) Endosperm development: Cellularization and cell fate specification. Annu. Rev. Plant Physiol. Plant Mol. Biol. 52: 233-267

22. Feussner I, Wasternack C, Kindl H and Kuhn H (1995) Lipoxygenase-catalysed oxygenation of storage lipids is implicated in lipid mobilization during germination. Proc. Natl. Acad. Sci. USA 92: 11849-11853

23. Jiang LW, Phillips TE, Hamm CA, Drozdowicz YM, Rea PA, Maeshima M, Rogers SW and Rogers JC (2001) The protein storage vacuole: a unique compound organelle. J. Cell Biol. 155: 991-1002

24. Jones A (2000) Does the plant mitochondrion integrate cellular stress and regulate programmed cell death? Trends Plant Sci. 5: 225-230 